\title{
Crítica de Livros
}

\section{Química fascinante, central e utilitária}

«Química e Sociedade. A presença da Química na actividade humana», Escolar Editora e Sociedade Portuguesa de Química, 1990.

«A presença da Química na actividade humana» é o subtítulo do livro «Química e Sociedade» (uma colecção?), lançado recentemente pelos editores Alberto Romão Dias e Joaquim J. Moura Ramos e pelas editoras Escolar Editora e Sociedade Portuguesa de Química. A todos: parabéns.

O livro de Ciência português é raro. O livro de Química português é raríssimo. Motivos para saudarmos, desde logo, esta nova publicação. Seríamos, porém, muito injustos se atribuíssemos o seu mérito apenas a contingências linguísticas. Em 1983, a Sociedade Portuguesa de Química promoveu um ciclo de conferências subordinadas ao tema «Química e Sociedade».

Foi um êxito. O livro que agora se apresenta ao público tem as suas raízes nessa iniciativa. Composto de onze artigos, de temas diversificados mas sempre na perspectiva da influência da Química no homem como ser eminentemente social, esta publicação apresenta um conteúdo em geral bem organizado, focando por vezes aspectos surpreendentes de intervenção da Ciência, a par de uma cuidada imagem gráfica.

Os dois primeiros temas abordados apresentam alguma complementariedade, partindo do geral - Evolução Química no Espaço e no Sistema Solar (Joaquim J. Moura Ramos) - para o particular - Evolução Química na Terra (Hernani Maia); são, por um lado, informativos e, por outro, interrogativos, debatendo entre observações concretas e indícios criteriosos o Problema da Origem da Vida.

O sinal da Química na permuta informativa, como elemento distintivo entre vida e não-vida, matéria orgânica e inorgânica, é a tese argumentada de uma forma simples mas convincente em Moléculas da Vida (Ana Lobo).

Os efeitos na saúde - bem-estar físico, mental e social - do desenvolvimento químico dos medicamentos, antibióticos e analgésicos em particular, desenvolve-se em Química e Saúde (Eduarda Rosa e Fátima Norberto).

Na relação da Química com a Pré-História (J. M. Peixoto Cabral) desenrola-se aos nossos olhos a evolução da Arqueo- logia ao longo dos tempos, a descoberta das potencialidades do isótipo ${ }^{14} \mathrm{C}$ e o seu impacto fundamental no estudo da cronologia da Pré-História.

Sobre a Fotografia (Eurico C. Melo) ficamos a conhecer os variados processos da Química-Física subjacentes à sua produção, desde a constituição de uma superfície sensível à luz até à sua lavagem final, passando pelos mecanismos "mágicos" da formação da imagem, sua revelação e fixação. Em Química na Arte (Maria Alzira A. Ferreira) discorre-se sobre os fenómenos químicos inerentes à realização de obras de arte; e, também, daqueles que as deteoram, limpam e conservam. São abordados, ainda, os métodos mais comuns de análise química de obras, realçando-se, em especial, os relativos à pintura.

O contributo da Química-adubos e pesticidas - no Aumento da Produção Agrícola (Joaquim Quelhas dos Santos) é apresentado numa versão positiva, tendo como exemplo dominante o caso português.

A Química em comuns preparados culinários - onde não faltam conselhos úteis - é iniciada em a Química e a Alimentação (Vera Sá da Costa).

A colaboração da Análise Química com a justiça (António Silva Santos), na detecção de crimes químicos e, principalmente, no "mundo da droga" é outro dos temas expostos neste livro.

Por fim, descreve-se a ligação entre a Química e a Guerra (António Pinho de Aguiar),com relevo para a "guerra dos gases químicos", introduzida em 1915 nas fronteiras da Bélgica.

Por entre a profusão dos temas tratados, o leitor-químico ou não - encontrará, decerto, numerosos motivos de interesse. Como é facto corrente em publicações desta natureza, a uniformidade não é uma constante ao longo das 220 páginas da «Química e Sociedade». O fiel, porém, inclina-se decisivamente para a região de bons ventos.

Uma palavra, indispensável, pela capa, de Rui Perdigão. Um espaço interestelar? Células entre células? Explosões químicas ao desvario? De bom efeito.

RAQUEL GONÇALVES

Faculdade de Ciências de Lisboa 
Auto-Retrato de um Químico Apaixonado

\section{«O Sistema Periódico» de Primo Levi (1919-1987), tradução portuguesa, Gra- diva 1988.}

Se nâo me engano, todos escrevíamos poesias, excepto Ettore, que dizia que isso não ficava muito bem a um engenheiro.

Capítulo «Ouro», p. 101

$O$ que era aquela química que me enfurecia a mime ao Tenente? Água e lume, mais nada, tal como na cozinha. Uma cozinha é certo, menos apetitosa, com odores penetrantes ou desagradáveis em vez dos aromas domésticos.

Capítulo «Níquel», p. 63

Sentia certa altivez parva por ter confirmado uma hipótese $e$ por ter desencadeado uma força da natureza.

Capítulo «Hidrogénio», p. 26

Para o incauto que apenas leia o título do livro sem o folhear, decerto se lembrará do arranjo químico de Mendeleev onde na célebre tabela os elementos foram escritos em linhas horizontais e verticais, elementos que repetem certas propriedades periodicamente tal como os sons harmónicos das notas de um pianó se repetem em intervalos de oitavas. E foi pegando em 21 desses elementos químicos - «Cada um dos elementos químicos diz alguma coisa a alguém» (p. 187) - que Primo Levi, judeu, químico, um dos «partagiani», sobrevivente $\mathrm{n}^{0} 174517$ do campo de Buna - Monowitz, uma filial de Auchwitz, poeta e escritor, nos revela, em 1975, no Il sistema periódico uma biografia fascinante, memórias, tragédias, derrotas, triunfos, ficção, e «flashes» a que um químico e o leitor em geral não conseguirá ficar alheio. Como verdadeiro alquimista metafórico, este escritor nato transforma cada elemento químico numa aventura e experiência do seu passado. À parte os capítulos dedicados ao "Chumbo» e «Mercúrio» que são pura ficção, e os do «Enxofre» e "Titânio» em que Levi não intervém como personagem, todos os outros transportam-nos às suas reminiscências, às suas origens, aos tempos de jovem universitário, aos tempos de guerra, às vicissitudes de um homem de uma «raça diferente» numa prosa clara e poética.

É o próprio Levi que nos recorda no capítulo «Prata», ao celebrar o $25^{\circ}$ aniversário da sua licenciatura, numa partilha de uma história com Cerrato, seu condiscípulo, o objectivo da sua escrita:

«Disse-lhe [Cerrato] que andava à procura de histórias minhas e de outros, que queria inseri-las num livro para ver se conseguia canalizar os leigos para o sabor forte e amargo da nossa profissão que é, assim, um caso particular numa versão mais destemida da profissão de viver. Disselhe que não me parecia correcto que o mundo soubesse tudo sobre a vida do médico, da prostituta, do marinheiro, do assassino, da condessa, do antigo romano, do conjurado e do polinesiano e nada de como vivemos nós transformadores da matéria» [«Prata», p. 16].

E é para esta transformação da matéria que a escrita de Levi adiciona ao sabor de cientista o de contador de histórias, histórias que vão desde as experiências de um adolescente, em que foca o encanto e a intimidação do laboratório, o «lugar sagrado» (capítulo «Hidrogénio» - por sinal o elemento mais leve) até ao humor com que descreve no capítulo «Azoto" a necessidade da extracção de um produto a partir do excremento de galinhas para a fabricação de um bâton. "A matéria é matéria, nem nobre nem vil, infinitamente transformável e efectivamente não interessa saber qual seja a sua origem mais próxima» [«Azoto», p. 148], e é esta matéria o lema exposto de modo singular, verdadeiro retrato de várias experiências profissionais e pessoais.

Nascido em Turim em 1919, licenciado em Química com 110 e louvor, a nota máxima, em 1941, a Química foi-lhe fonte de vida: ocupou um lugar de destaque numa indústria química até 1977, ano em que se reforma (só a partir dessa data é que Levi se dedica completamente à escrita até 11 de Abril de 1987, data da sua morte); e acima de tudo, o facto de possuir um documento de licenciado em Química permitiu-lhe sobreviver num campo de concentração que foi libertado pelos Russos em Janeiro de 1945. Este último facto é tão marcante que faz dessa época tema para os seus dois livros mais conhecidos - "Se questo é un uomo» (Einaudi, 1958) (tradução portuguesa: «Se isto é um homem», Teorema, 1988) e La tregua (A trégua) (Einaudi, 1963) - e que aqui recorda nos capítulos "Cério» e «Vanádio». No primeiro capítulo do livro, servindo-se dos gases inertes e raros, Levi descreve as suas próprias raízes, leva-nos à cultura dos judeus Piemonteses, através de inúmeras inserções de uma língua curiosa - o iídiche - um dialecto hebraico, aliás, que aparece logo no início do livro como epígrafe em forma de provérbio (No texto original Levi atribui equivocadamente o Prémio Nobel ao investigador que conseguiu «obrigar» o xénon a reagir com o flúor. $\mathrm{Na}$ realidade, embora Neil Bartlett, o investigador em causa, tenha recebido mais de uma dezena de Prémios e Medalhas Científicas ainda não foi galardoado com o Prémio Nobel). Em seguida revisita o laboratório, «o lugar para jovens» (p. 162), fonte de alegria e de fascínio intenso da descoberta, da aventura, do imprevisto, da explosão e do medo e termina com o ciclo do carbono, esse elemento-chave da vida, elemento singular que forma cadeias estáveis, longas cadeias que se inserem no mundo vegetal e animal. Em muitos dos capítulos sentimos o relembrar da nossa própria vivência: a memória da primeira experiência realizada, a electrólise da água, ou a tentativa de prepararóxidonitroso, o gás hilariante que fez furor na época de Humphry Davy (Capítulo «Hidrogénio»), as aulas de Química Geral e Inorgânica, os episódios dos exames e os vários Caselli que fomos conhecendo, esses fidelíssimos ratos de laboratório tão umbilicalmente ligados ao Mestre (Capítulo «Zinco») ou ainda os acidentes como o narrado no Capítulo "Potássio». Recordações que nos dão a consciência de que a química é também repetição de ritmos de tarefas semelhantes, silenciosas, em que a metamorfose é centro e coisa sagrada. 
Falemos agora da tradução portuguesa vinda a público em 1988 pela mão da Gradiva. É evidente e de forma notória que a tradução não foi suficientemente cuidada do ponto de vista técnico - os erros são demasiado abundantes e graves, pelo que se recomenda a inserção de uma errata - e apresenta ainda alguns erros de palmatória, no geral. Logo em relação ao título do livro seria mais sugestivo e justificativo o nome de «A Tabela Periódica» em vez de «O Sistema Periódico». Em relação aos erros não-técnicos, os mais graves aparecem-nos na interpretação de «i suoi di lei» (p. 61) traduzido como «os seus de lei», quando se pretende "parentes», na má tradução referente a «obra» (p. 64) quando se pretendia OVRA (agente da polícia secreta de Mussollini), Hermes Trimegisto em vez de Hermete (p. 82), Ceres (o asteróide) em vez de Cerere (p. 115). Quanto aos erros de natureza técnica a gravidade é maior e indicam-se aqui alguns na versão correcta: tornesol em vez de tornassol (p. 25), secar em vez de enxugar (p. 30, p. 154), radicais alquílicos: metilo, butilo em vez de radicais alcoílos: metileno, butileno (p. 30), bromo em vez de brómio (p. 35), Hottes em vez de trombas de aspiração (p. 36), anião em vez de anion (p. 38), poder rotatório em vez de poder giratório (p. 47), trompa em vez de tromba (p. 73), moagem, peneiraçâo em vez de polimento e peneiradas (p. 65), cromato em vez de cromados (pp. 121, 124 e 127), arsénio em vez de arsénico (p. 137, título de capítulo), anidrido arsernioso em vez de anidrido de arsénico, aque-ceu-se em vez de escaldávamos (p. 138), gasolina em vez de benzina (p. 139), serpentina de arrefecimento em vez de refrigerador (p. 139), reacções com dois sentidos em vez de reacção bífida (p. 166). No total foram detectadas mais de sessenta incorrecções. É de lamentar ainda a não-introdução de uma nota biográfica que viria muito a propósito já que a primeira tradução em língua portuguesa de um livro do autor de Ad Ora Incerta aparece cerca de trinta anos após a sua iniciação literária.

A falta de livros de temática que aproximam os vários tipos de saber, a qualidade literária, o sabor de uma inteligência aguda e muitas vezes o paladar aforístico leva-nos a aconselhar vivamente a leitura atenta de «O Sistema Periódico», mesmo a tradução portuguesa apesar dos erros nela existentes.

\section{Lista das principais publicaçōes de Primo Levi:}

Se questo é un uomo, Einaudi, 1958;

La tregua, Einaudi, 1963;

Storia naturalli (pseudonimo Damiano Malabaila), 1966;

Vizio di forma, Einaudi, 1971;

Il sistema periódico, Einaudi, 1975 (tradução portuguesa: «O Sistema Periódico», Gradiva, 1988);

Lilít e altri raconti, Einaudi, 1981;

Se non ora, quando, Einaudi, 1982 (tradução portuguesa: «Se não agora, quando?, D. Quixote, 1988);

Ad ora incerta (Colectânea de poemas), Garzanti, 1984;

L'autri mestiere, Einaudi, 1985;

I sommersi e i salvati, Einaudi, 1986.

A. M. NUNES DOS SANTOS

Faculdade de Ciências e Tecnologia da Universidade Nova de Lisboa

\section{Nem só Jogadores de Futebol, Novelas e Dentistas vêm do Brasil}

\section{«Como se faz Química. Uma reflexão sobre a Química e a Actividade do Químico». (Aécio Pereira Chagas, Editora da UNI- CAMP, Campinas, S. Paulo, Brasil)}

A Ciência é um assunto absorvente e são muito poucos os cientistas activos que encontram tempo para ensinar (e cativar) os não iniciados. É um facto da vida, mas é pena. Até porque muitos daqueles que nos financiam os brinquedos não se apercebem da importância cultural (e eventualmente prática) dos nossos jogos. Em Portugal, onde até a investigação científica se confunde com desenvolvimento tecnológico, talvez estejamos a pagar o preço da nossa «arrogância intelectual». A obcessão pela Ciência faz-nos esquecer que o nosso produto também está sujeito às regras do «marketing». Um público profundamente ignorante em matéria de Ciência, é também um público totalmente desinteressado das questões científicas. Do que não se entende não se fala e se não se entende não é importante.

Como é que se põe um leigo a falar de Ciência, de Química em particular? Há, por certo, várias receitas, mas infelizmente não conheço nenhuma ensaiada em Portugal. É por isso que quero chamar a atenção para um pequeno e despretencioso livro escrito por Aécio Pereira Chagas, professor da Universidade Estadual de Campinas (UNICAMP), Brasil. Em apenas 90 páginas o autor tenta dar uma visão global da Química, dos seus métodos, da sua relação com a vida e com a sociedade. O texto é duma simplicidade extrema, aflorando questões como a estrutura e reactividade das moléculas, a síntese, purificação e identificação de substâncias. O esforço do autor para evitar termos técnicos foi, em grande parte, conseguido. O último capítulo do livro, onde se explica o papel das sociedades de química, é dedicado à profissão de químico e inclui também informações úteis para os estudantes brasileiros que ponderem exercer uma actividade neste domínio.

Embora o livro seja de leitura muito agradável, e por isso o recomendo vivamente aos alunos do secundário e a pessoas sem qualquer formação na área da Química, julgo que para nós, Químicos, mais importante é a demonstração de que é possível ser-se um excelente cientista, como acontece com o autor, um dos melhores químicos brasileiros, e gastar algum tempo numa actividade cada vez mais essencial nos nossos dias.
J. A. MARTINHO SIMŌES Instituto Superior Técnico 

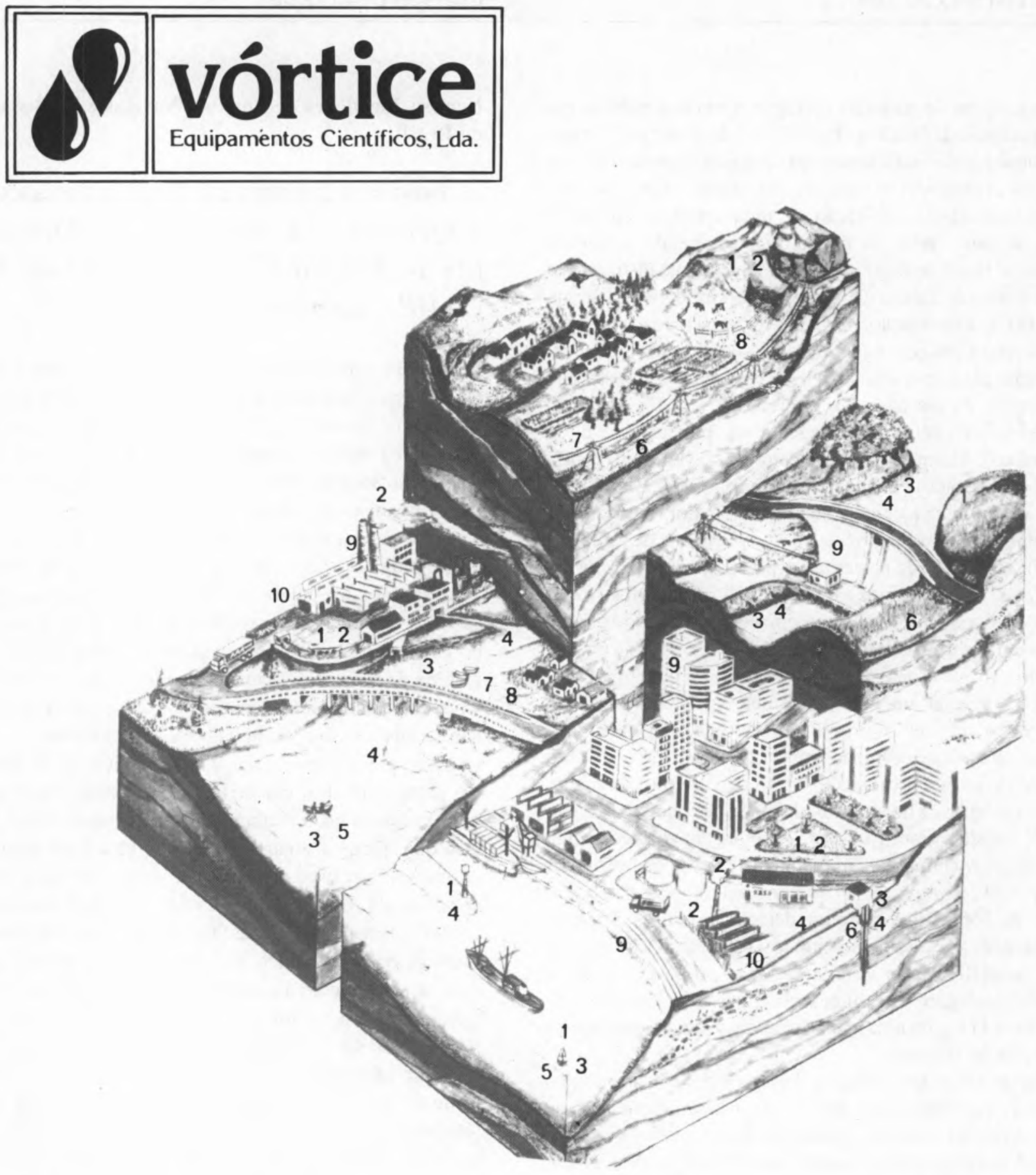

1 Meteorologia - Medição da temperatura, humidađe, pressao, vento, precipitação, evaporação, etc.

2 Poluigão do ar - Ambiente e emissão - Medição da concentração de poeiras e gases (dióxido de enxofre, óxidos de azoto, monóxido de carbono, hidrocarbonetos, ozono, etc.).

3 Poluigräo da água - Mediçẫo de $\mathrm{pH}$, temperatura, oxigénio dissolvido, condutividade, potencial redox, turbidez, caudal, obtenção de amostras, etc.

4 Midrometria - Medição de niveis, velocidades e caudais.

5 Oceanografía - Medição de correntes, pressōes, temperaturas, condutividades, salinidades, niveis de marés, amplitude de ondas, etc.

6 Goofísica - Medição de parâmetros utilizados em prospecção sísmica, geoeléctrica, obtenção de diagrafias eléctricas, etc.

7 Fisiologia Vegetal - Equipamentos para medição da porosidade das folhas, medição da área foliar, etc.

8 Teste do solos - Amostradores de solos, penetrómetros, permeâmetros, etc.

9 Comportamento estrutural - Medição de extensōes, deslocamentos, vibrações, assentamentos, temperaturas, etc.

10 Controlo de Processo Industrial - Medição de temperatura, humidade, pressão, pH, oxigénio dissolvido, condutividade, potencial redox, turbidez, nivel, caudal, etc.

CENTRO EMPRESARIAL TEJO Rua de Xabregas, 20, Piso 2, Esc. 2.04 - 1900 Lisboa - Portugal Telefones (01) 383559 / 383699 . Telex 42369 DEPICO P 